\title{
Evaluasi Program Pos Pembinaan Terpadu Penyakit Tidak Menular (Posbindu PTM)
}

\author{
Rika Risalam Mahdur', Wahyu Sulistiadi ${ }^{2}$ \\ ${ }^{1}$ Program Studi S1 Ekstensi Fakultas Kesehatan Masyarakat, Universitas Indonesia \\ ${ }^{2}$ Dosen Fakultas Kesehatan Masyarakat, Universitas Indonesia
}

\begin{abstract}
Abstrak
Latar Belakang: Salah satu permasalahan saat ini yang dihadapi dalam pembangunan kesehatan Indonesia adalah beban ganda penyakit, dimana masih banyaknya penyakit infeksi yang harus ditangani dan semakin meningkatnya penyakit tidak menular (PTM). Untuk mengendalikan PTM, sistem pengelolaan program-program kesehatan yang ada perlu dievaluasi. Salah satu program kesehatan yang erat kaitannya dengan upaya pengendalian PTM adalah program posbindu PTM yang dikembangkan oleh Kemenkes RI.

Metode: penelitian ini menggunakan metode literature review dengan menggunakan database google cendikia.

Hasil: Hasil penelitian terhadap evaluasi program posbindu PTM di berbagai daerah tersebut dibagi menjadi evaluasi input, proses, dan output dan disetiap indikator evaluasinya masih ditemukan masalah dalam pelaksanaannya.

Kesimpulan: hasil evaluasi ini diharapkan bisa menjadi pertimbangan untuk perencanaan program posbindu PTM yang lebih baik lagi, bisa diterapkan sesuai dengan kemampuan masyarakat serta adanya kolaborasi antar lintas sektoral.
\end{abstract}

Kata Kunci: Evaluasi program, Penyakit tidak menular, Posbindu PTM

\section{Evaluation Of Posbindu PTM}

\begin{abstract}
Background: One of the problems currently facing in Indonesia's health development is a burden double disease where there are many infection diseases which should be handled and the increasing noncommunicable disease (NCD). To control NCD, health programs management systems should be evaluated. One of the programs health that were closely related with the effort to control NCD is Posbindu PTM developed by the ministry of health of the Republic of Indonesia.

Methods: The method used is literature review using google scholar database.

Result: The outcome of research on evaluating the posbindu PTM in various areas were split into input, process, and output indicators and on their evaluations there were problems in its implementation.

Conclusion: The evaluation was expected to be consideration for planning for posbindu PTM better, workable according to the ability of the community, and also The collaborative sectors.
\end{abstract}

Keywords: Evaluation, Noncommunicable Disease, Posbindu PTM

\footnotetext{
Alamat Korespondensi :

Rika Risalam Mahdur

Fakultas Kesehatan Masyarakat, Universitas

Indonesia, Depok

Email: rikarisalamm@gmail.com
} 


\section{PENDAHULUAN}

Salah satu permasalahan saat ini yang dihadapi dalam pembangunan kesehatan di Indonesia adalah beban ganda penyakit, dimana masih banyaknya penyakit infeksi yang harus ditangani dan semakin meningkatnya penyakit tidak menular (PTM). Hasil Riskesdas Kemenkes RI tahun 2018 menunjukkan trend PTM di Indonesia seperti diabetes mellitus, hipertensi, dan obesitas meningkat dibandingkan Riskesdas tahun 2013. ${ }^{1}$ Apabila PTM tidak dikendalikan akan mengakibatkan komplikasi, kecacatan, kematian, serta tingginya beban biaya pengobatan. Untuk mengendalikan PTM, sistem pengelolaan program-program kesehatan yang ada di Indonesia perlu dibenahi.

Salah satu program kesehatan yang erat kaitannya dengan upaya pengendalian PTM adalah program posbindu PTM yang dikembangkan oleh Kementerian Kesehatan Republik Indonesia. Posbindu PTM merupakan bentuk peran serta masyarakat dalam upaya pengendalian faktor risiko secara mandiri dan berkesinambungan Faktor risiko penyakit tidak menular (PTM) diantaranya merokok, konsumsi minuman beralkohol, pola makan tidak sehat, kurang aktifitas fisik, obesitas, stres, hipertensi, hiperglikemi, hiperkolesterol, dan menindaklanjuti secara dini faktor risiko yang ditemukan melalui konseling kesehatan dan segera merujuk ke fasilitas pelayanan kesehatan dasar. $^{2}$

Cara untuk mengetahui permasalahan penerapan suatu program dapat dilakukan dengan mengevaluasinya pada saat pelaksanaan dan atau pada akhir pelaksanaan program. Evaluasi program kesehatan adalah proses menyediakan informasi mengenai sejauh mana program kesehatan tercapai, perbedaan pencapaian dengan suatu standar, serta manfaat yang telah didapatkan dari program kesehatan yang telah dilaksanakan untuk merumuskan alternatif keputusan dimasa yang akan datang. Pendekatan evaluasi program posbindu PTM untuk meningkatkan pencapaian cakupan dapat dilakukan dengan pendekatan teori sistem. Teori sistem dibagi menjadi tiga yaitu input, proses, dan output. Pendekatan teori sistem akan memberikan gambaran holistik tentang hal-hal yang perlu dipertahankan, ditingkatkan, dan digantikan sebagai upaya meningkatkan cakupan layanan di posbindu PTM menjadi maksimal dan pengendalian penyakit tidak menular di Indonesia.

\section{METODE}

Metode yang digunakan dalam penulisan ini adalah literature review dengan menggunakan database google scholar atau google cendikia. Pencarian jurnal-jurnal diperoleh menggunakan kata kunci "evaluasi program posbindu PTM" kemudian dispesifikasi dari tahun 2015 sampai 2019. Selanjutnya, terpilih 10 jurnal sebagai berikut:

Tabel 1 Daftar Jurnal

\begin{tabular}{|c|c|c|}
\hline No & Penulis & Jurnal \\
\hline 1 & $\begin{array}{l}\text { Ambarwati, } \\
\text { Ferianto } \\
(2019)\end{array}$ & 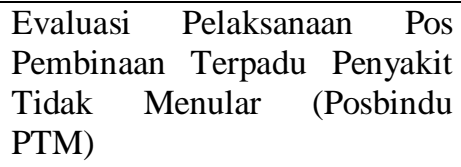 \\
\hline 2 & $\begin{array}{l}\text { Dhany, grace } \\
\text { sicilia (2018) }\end{array}$ & $\begin{array}{lcc}\text { Evaluasi } & \text { kualitatif } & \text { program } \\
\text { penyakit } & \text { tidak } & \text { menular } \\
\text { berbasis Posbindu di } & \text { wilayah } \\
\text { kerja Puskesmas Muara Bungo } \\
\text { I }\end{array}$ \\
\hline 3 & $\begin{array}{l}\text { Febrianti dan } \\
\text { Prabawati } \\
(2017)\end{array}$ & $\begin{array}{l}\text { Implementasi Pelaksanaan Pos } \\
\text { Pembinaan Terpadu Penyakit } \\
\text { Tidak Menular (Posbindu } \\
\text { PTM) Di Puskesmas Pucang } \\
\text { Sewu Kota Surabaya }\end{array}$ \\
\hline 4 & $\begin{array}{l}\text { Irmawati dkk } \\
\text { (2018) }\end{array}$ & $\begin{array}{l}\text { Analisis Pelaksanaan Program } \\
\text { Pos Pembinaan Terpadu } \\
\text { penyakit Tidak Menular Di } \\
\text { Wilayah Kerja Puskemas } \\
\text { Srondol Kulon, Kota Semarang } \\
\text { (Studi Kasus di RW 13, } \\
\text { Kecamatan Srondol Wetan, } \\
\text { Kelurahan Banyumanik) }\end{array}$ \\
\hline 5 & $\begin{array}{l}\text { Paramita dkk } \\
\text { (2019) }\end{array}$ & $\begin{array}{l}\text { Optimalisasi Pos Pembinaan } \\
\text { Terpadu Penyakit Tidak } \\
\text { Menular Di Desa Loa Kumbar, } \\
\text { Kecamatan Sungai Kunjang, } \\
\text { Kota Samarinda, Kalimantan } \\
\text { Timur }\end{array}$ \\
\hline 6 & $\begin{array}{l}\text { Pranandari } \\
\text { dkk (2017) }\end{array}$ & $\begin{array}{l}\text { Analisis Implementasi Program } \\
\text { Pos Pembinaan Terpadu } \\
\text { Penyakit Tidak Menular } \\
\text { (Posbindu PTM) Di } \\
\text { Kecamatan Banguntapan } \\
\text { Kabupaten Bantul } \\
\end{array}$ \\
\hline 7 & $\begin{array}{l}\text { Primiyani dkk } \\
\text { (2019) }\end{array}$ & $\begin{array}{l}\text { Analisis Pelaksanaan Program } \\
\text { Pos Pembinaan Terpadu } \\
\text { Penyakit Tidak Menular di } \\
\text { Kota Solok }\end{array}$ \\
\hline 8 & $\begin{array}{ll}\text { Putri } & \text { dkk } \\
(2018) & \end{array}$ & $\begin{array}{l}\text { Evaluasi Proses Implementasi } \\
\text { Posbindu PTM Di Wilayah } \\
\text { Kerja Puskesmas Simpang } \\
\text { Sungai Duren Kecamatan } \\
\text { Jambi Luar Kota Kabupaten } \\
\text { Muaro Jambi Tahun } 2017\end{array}$ \\
\hline 9 & $\begin{array}{l}\text { Suhbah dkk } \\
\text { (2019) }\end{array}$ & $\begin{array}{l}\text { Evaluasi Pelaksanaan Program } \\
\text { Pos Pembinaan } \quad \text { Terpadu }\end{array}$ \\
\hline
\end{tabular}




\begin{tabular}{|l|ll|l|}
\hline & & & $\begin{array}{l}\text { Penyakit Tidak Menular } \\
\text { (Posbindu PTM) Puskesmas } \\
\text { Sukolilo I Kabupaten Pati }\end{array}$ \\
\hline 10 & Yanti dkk & $\begin{array}{l}\text { Analisis Implementasi } \\
\text { Kebijakan Puskesmas Dalam } \\
(2019)\end{array}$ & $\begin{array}{l}\text { Program Pos Pembinaan } \\
\text { Terpadu Penyakit Tidak } \\
\text { Menular }\end{array}$ \\
\hline
\end{tabular}

Ke-10 jurnal tersebut dipilih sebagai gambaran pelaksanaan posbindu PTM di Indonesia untuk mengevaluasi program posbindu PTM yang sudah berjalan di Indonesia.

\section{HASIL}

Dari berbagai penelitian terhadap evaluasi program posbindu PTM di berbagai daerah tersebut dibagi menjadi evaluasi input, proses, dan output. Indikator pada evaluasi input terdiri dari :

\section{Sumber daya manusia (SDM)}

Penelitian Suhbah dkk di Puskesmas Kabupaten Pati tahun 2019 dilihat dari aspek sumber daya manusia sudah mencukupi dalam pelaksaan posbindu PTM. SDM yang ada di kabupaten Pati belum semuanya memilki kompetensi yang cukup, sertifikat khusus maupun SK Posbindu PTM. ${ }^{3}$ Penelitian lain di Puskesmas daerah Surabaya mengemukakan bahwa sumber daya manusia berdasarkan kualitas dan kuantitas baik dari tenaga medis maupun kesehatan lainnya dalam memberikan pelayan sudah cukup baik tetapi masih ada kendala dari kurangnya tenaga medis yang diharapkan bisa datang pada setiap pertemuan Posbindu PTM. ${ }^{4}$ Hal ini juga didukung oleh penelitian Pranandari dkk tahun 2017 bahwa pelaksanaan posbindu PTM terdapat ketergantungan antara anggota kader dengan ketua kadernya ini mengakibatkan apabila ketua kader berhalangan hadir dalam Posbindu PTM maka program tidak berjalan. ${ }^{5}$

\section{Pembiayaan atau Dana}

Sumber dana program Posbindu PTM di wilayah Pati berasal dari BOK (Biaya Operasional Kesehatan) dan dana desa. Dana BOK hanya dialokasikan untuk kegiatan pembinaan dan pelayanan Posbindu PTM selama dua kali pertemuan dalam setahun, sementara dana desa belum semua Desa menganggarkannya. ${ }^{3}$ Hal ini sangat berbeda dengan penelitian
Primiyani dkk tahun 2019 di wilayah Solok posbindu PTM didanai melalui APBD maupun BOK puskesmas meliputi kegiatan pengadaan alat kesehatan, pembelian reagensia laboratorium, pencatatan dan pelaporan, sosialisasi ke masyarakat, skrining bagi petugas, transport petugas ke posbindu, pelatihan dan pembinaan kader posbindu, serta honor kader. ${ }^{6}$

\section{Sarana dan Prasarana}

Penelitian Febrianti tahun 2019 mengemukakan bahwa fasilitas yang tersedia di Puskesmas untuk mendukung posbindu PTM sudah cukup baik, baik gedung maupun alat kesehatannya tetapi masih perlu menambahkan alat kesehatan pada setiap Posbindu yang ada karena selama ini masih memakai peralatan kesehatan Posyandu Balita. ${ }^{4}$ Penelitian lain dari Suhbah dkk tahun 2019 juga mengemukakan terdapat keterbatasan sarana dan prasarana Posbindu PTM. ${ }^{3}$ Selama ini, sarana dan prasarana yang digunakan hanya timbangan, alat ukur tinggi badan, alat ukur lingkar perut, tensimeter, alat pemeriksaan kolesterol, alat pemeriksaan asam urat, alat pemeriksaan gula darah serta kartu menuju sehat Faktor Risiko Penyakit Tidak Menular (KMS FR-PTM) dan buku pencatatan Kader untuk kegiatan pencatatan dan pelaporan. Sarana prasarana yang tersedia juga masih terdapat kendala seperti beberapa timbangan yang digunakan dalam pengukuran berat badan tidak berfungsi dengan baik.

Indikator selanjutnya adalah evaluasi proses terkait implementasi program posbindu PTM. Penelitian Irmawati dkk tahun 2018 Implementasi Program Posbindu PTM di wilayah Srondol Kulon belum berjalan hanya terdapat program posbindu untuk para lansia. Penelitian lain posbindu PTM di Wilayah Jambi telah memenuhi Standar Operasional Prosedur (SOP) diantaranya waktu pelaksanaan, pelaksanaan kegiatan, peran petugas puskesmas, serta pencatatan dan pelaporan sedangkan yang belum memenuhi SOP diantaranya tempat pelaksanaan, peran kader, peran pemangku kepentingan dan pembiyaan Posbindu PTM. ${ }^{8}$ Penelitian terbaru dari Ambarwati dan Ferianto tahun 2019 mengemukakan bahwa pengetahuan responden tentang Posbindu PTM cukup baik, sikap bidan desa, kader dan warga tentang Posbindu PTM sangat mendukung dan akan mengikuti kebijakan pemerintah meskipun dalam praktiknya belum 
maksimal sesuai petunjuk teknis posbindu PTM tahun 2012. ${ }^{9}$

Evaluasi output dari program posbindu PTM bisa dilihat dari cakupan program tersebut. Output yang kurang memuaskan ditunjukkan oleh penelitian Dhany tahun 2018 dalam kurun waktu 3 tahun posbindu di Muara Bungo berjalan secara berkelanjutan yang dilaksanakan satu kali setiap bulan dengan capaian kunjungan posbindu masih rendah yaitu: 5,7\% (kurang dari 10\%). ${ }^{10}$ Selain itu, Evaluasi setelah pelaksanaan kegiatan posbindu PTM belum dilakukan secara khusus poin per poin Penelitian di Jambi mengemukakan waktu pelaksanaan Posbindu PTM telah memenuhi Standar Operasional Prosedur (SOP) minimal satu kali dalam sebulan. Kehadiran peserta masih sedikit meskipun pelaksanaannya tidak hanya satu kali dalam sebulan karena masyarakat banyak yang bekerja pada hari dan waktu tersebut. ${ }^{8}$ Pada gambaran output posbindu PTM hasil penelitian Primiyani dkk tahun 2019 di kota Solok dalam kurun waktu empat tahun belum optimal dilihat dari capaian kunjungan posbindu masih rendah terlihat dari hasil masyarakat yang melakukan pemeriksaan tekanan darah hanya $15,59 \%{ }^{6}$

\section{PEMBAHASAN}

Evaluasi dilakukan berdasarkan pendekatan sistem yaitu input, proses, dan output. Indikator input yang dievaluasi diantaranya sumber daya manusia, pendanaan, serta sarana prasarana. Dilihat dari sumber daya manusia yang ada di posbindu PTM sudah cukup baik secara kuantitas tetapi belum secara kualitasnya. Apabila sudah sesuai kualitasnya tidak mungkin terjadi ketergantungan yang menghambat pelaksanaan posbindu PTM. Berdasarkan petunjuk teknis Posbindu PTM oleh Kemenkes RI tahun 2016, pelaksanaan posbindu PTM dilakukan oleh kader posbindu PTM dengan kriteria berpendidikan minimal SLTA, serta mau dan mampu melakukan kegiatan berkaitan dengan Posbindu PTM. Kriteria kader posbindu diperbaharui lagi didalam petunjuk teknis posbindu PTM bagi kader diantaranya memiliki kriteria bisa baca dan menulis, mau dan mampu, serta terlatih bersertifikat paling kurang mendapat surat keterangan sudah dilatih dari Puskesmas pembinanya. ${ }^{11}$ Dengan adanya kriteria yang lebih spesifik, diharapkan Kementerian Kesehatan dapat memberikan dukungan baik sarana maupun prasarana yang dapat mendukung untuk mencapaian kader posbindu PTM yang sesuai kriteria. Ketika kader posbindu PTM telah sesuai dengan kriteria dapat mendukung pengendalian PTM di masyarakat karena kader merupakan bagian dari masyarakat. Hal ini sejalan dengan pendapat Paramita dkk tahun 2019 bahwa komitmen masyarakat menjadi kunci untuk mewujudkan Posbindu PTM yang mandiri dan berkelanjutan serta penanggulangan PTM. ${ }^{12}$

Indikator kedua dalam input yang dievaluasi adalah pendanaan/pembiayaan. Pendanaan terhadap pembiayaan di setiap daerah berbeda-beda. Posbindu PTM saat ini lebih mengandalkan dana dari masyarakat padahal posbindu PTM merupakan program promotif preventif yang semestinya sudah ada proporsi dananya di anggaran kesehatan. Seperti yang kita ketahui, 2/3 dari anggarannya kesehatan diperuntukkan untuk kepentingan pelayanan publik. ${ }^{13}$ Sumber dana yang sedikit tidak jarang menjadi penghambat dalam pelaksanaan program. Kurangnya sumber dana sangat berpengaruh seperti kinerja kader menjadi kurang optimal dan kurangnya motivasi masyarakat untuk mengikuti Posbindu PTM dikarenakan harus membayar untuk pemeriksaan. ${ }^{8}$ Oleh karena itu, perlunya peningkatan koordinasi dan kemampuan dalam menjalin kemitraan untuk memenuhi kebutuhan proses implementasi Posbindu PTM. Dalam mendukung terselengggaranya posbindu PTM, Yanti dkk tahun 2019 mengemukakan perlunya pembiayaan yang memadai baik dana mandiri atau dukungan dari pihak lain di wilayah masing-masing. ${ }^{14}$ Salah satunya melalui Pemerintah Daerah setempat melalui dukungan kebijakan termasuk pembiayaan secara berkesinambungan. Tanpa adanya sarana dan prasarana serta anggaran dana, maka implementasi kebijakan tidak akan berhasil. ${ }^{7}$

Indikator ketiga dalam input yang dievaluasi adalah sarana prasarana yang tersedia di Posbindu PTM. Berdasarkan penelitianpenelitian sarana prasarana yang ada sudah cukup baik dan memenuhi kelengkapan minimal dalam petunjuk teknis posbindu PTM tahun 2019. Kelengkapan minimal yang ditentukan Kemenkes RI tahun 2019 yaitu tersedianya alat pengukuran tekanan darah (tensimeter), glukometer, timbangan, alat pengukur tinggi badan, alat ukur lingkar perut/pita meteran, buku pemantauan peserta, serta buku pencatatan. ${ }^{11}$ Yang menjadi masalah dalam sarana prasarana adalah perlunya monitoring terhadap alat-alat 
pengukuran agar berfungsi dengan baik. Bila tidak ada dukungan sarana dan prasarana yang memadai mengakibatkan tujuan program Posbindu PTM tidak akan tercapai. ${ }^{3}$

Efek dari input posbindu PTM seperti sumber daya manusia, pendanaan, dan sarana prasarana yang kurang memadai menyebabkan saat implementasi tetap dilakukan sesuai SOP meskipun terdapat beberapa hambatan dan seadanya. Menurut Primiyani dkk tahun 2019 seharusnya sebelum melakukan pelaksanaan posbindu terlebih dahulu dibuat perencanaannya. ${ }^{6}$ Perencanaan yang telah dibuat oleh puskesmas disampaikan kepada kader di Posbindu supaya kader mengetahui kapan kegiatan posbindu berlangsung dan siapa saja petugas puskesmas yang ikut dalam kegiatan sehingga sebelum kegiatan dilaksanakan kader bisa mempersiapkan segala sesuatu yang diperlukan. Pelaksanaan implementasi posbindu PTM juga harus sesuai juknis SOP yang terbaru berdasarkan pedoman dari Kemenkes tahun 2019. Evaluasi yang terakhir adalah output. Berdasarkan hasil yang ditemukan seluruh posbindu PTM belum mencapai target cakupan. Meskipun target cakupan bukan menjadi satusatunya yang bisa dievaluasi di output tetapi cakupan menjadi indikator apakah program tersebut sudah tercapai atau belum. Hal ini juga dipertegas oleh Dhany dkk tahun 2019 bahwa Evaluasi pasca pelaksanaan kegiatan posbindu PTM belum dilakukan secara khusus poin per poin. ${ }^{10}$ Oleh karena itu, perlunya pelaksanaa posbindu PTM yang terintegrasi dengan program lainnya yang ada di masyarakat dan bekerja di dalam komunitas yang banyak organisasi dan keterlibatan kuat dari anggotanya.

Peran tenaga kesehatan masyarakat menjadi penting disetiap program mulai dari perencanaan hingga evaluasi. Dari evaluasi input kita bisa melihat pentingnya peran kesehatan masyarakat untuk advokasi masyarakat terkait SDM, dana, dan sarana prasarana. Saat proses pelaksanaan posbindu PTM, tenaga kesehatan masyarakat bisa melakukan pemberdayaan masyarakat agar sesuai dengan SOP di petunjuk teknis posbindu PTM dan dapat memandirikan masyarakat agar terciptanya pengendalian PTM melalui posbindu PTM yang berkelanjutan. Sehingga saat evaluasi akhir bisa dilihat dari output pelaksanaan posbindu PTM secara kuantitas maupun kualitasnya baik dan mendapatkan outcome yang diharapkan yaitu mengendalikan PTM. Selain itu, kerjasama antar sektoral sangat amat penting untuk mendukung capaian dari program posbindu PTM yang lebih baik.

\section{KESIMPULAN}

Berdasarkan evaluasi program pos pembinaan terpadu penyakit tidak menular (PTM) dengan pendekatan sistem (input, proses, dan output) masih memiliki kekurangan dan hambatan. Evaluasi input yang dilihat dari sumber daya manusia, pendanaan, serta sarana prasarana masih belum merata di seluruh daerah. Evaluasi proses dilihat dari bagaimana posbindu PTM tersebut dilaksanakan. Memang posbindu PTM sudah dilakukan secara rutin tetapi kualitas dari pelayanannya masih kurang memadai dan input yang belum memadai juga menjadi hambatan dalam proses pelaksanaan posbindu PTM. Sehingga evaluasi output dan outcome terlihat bahwa Posbindu PTM belum mencapai target dan outcomenya untuk mengendalikan PTM juga tidak tercapai. Hal ini harus menjadi evaluasi bagi Kementerian Kesehatan, Pemerintah pusat atau daerah, Masyarakat, dan tenaga kesehatan khususya kesehatan masyarakat. Untuk mencapai pengendalian PTM di Indonesia melalui posbindu PTM tidak hanya bisa dilakukan oleh satu sektor tetapi harus melibatkan pihak dari berbagai sektor. Dari evaluasi ini bisa menjadi pertimbangan untuk perencanaan program posbindu PTM yang lebih baik lagi dan bisa diterapkan sesuai dengan kemampuan masyarakat.

\section{DAFTAR PUSTAKA}

1. Kemenkes RI. Hasil Utama Riskesdas 2018. 2018.

2. Kemenkes RI. Pos Pembinaan Terpadu Penyakit Tidak Menular (POSBINDU PTM). 2012.

3. Suhbah W DA, Suryawati C, Kusumastuti W. Evaluasi Pelaksanaan Program Pos Pembinaan Terpadu Penyakit Tidak Menular (POSBINDU PTM) Puskesmas Sukolilo I Kabupaten Pati. Jurnal Kesehatan Masyarakat [Internet]. 2019 Oct 16 [cited 2020 Mar 11];7(4):647-57. Available from: https://ejournal3.undip.ac.id/index.php/i k m/article/view/24983 
4. Febrianti R, Prabawati I. Kabupaten Muaro Jambi Tahun 2017. J Implementasi Pelaksanaan Pos Pembinaan Terpadu Penyakit Tidak Menular (POSBINDU PTM) Di Puskesmas Pucang Sewu Kota Surabaya. Publika. 2017;5(5).

5. Pranandari LL, Arso SP, Fatmasari Ey. Analisis Implementasi Program Pos Pembinaan Terpadu Penyakit Tidak Menular (POSBINDU PTM) Di Kecamatan Banguntapan Kabupaten Bantul. Jurnal Kesehatan Masyarakat [Internet]. 2017 Nov 27 [cited 2020 Mar 11];5(4):76-84. Available from: https://ejournal3.undip.ac.id/index. php/jk m/article/view/18319

6. Primiyani Y, Masrul M, Hardisman H. Analisis Pelaksanaan Program Pos Pembinaan Terpadu Penyakit Tidak Menular di Kota Solok. J Kesehat Andalas. 2019;8(2):399.

7. Irmawati R, Wigati PA, Arso SP. Analisis Pelaksanaan Program Pos Pembinaan Terpadu Penyakit Tidak Menular Di Wilayah Kerja Puskemas Srondol Kulon, Kota Semarang (Studi Kasus di RW 13, Kecamatan Srondol Wetan, Kelurahan Banyumanik). Jurnal Kesehatan Masyarakat [Internet]. 2018 Jan 2 [cited 2020 Mar 11];6(1):57-70. Available from:

https://ejournal3.undip.ac.id/index. php/jk m/article/view/19834

8. Putri RE, Hubaybah, Asparian. Evaluasi Proses Implementasi Posbindu PTM Di Wilayah Kerja Puskesmas Simpang Sungai Duren Kecamatan Jambi Luar Kota

9. Ambarwati, Ferianto. Evaluasi Pelaksanaan Pos Pembinaan Terpadu Penyakit Tidak Menular (POSBINDU PTM). Jurnal Profesi Keperawatan. 2019 Mar 19;6(1).

10. Dhany grace sicilia. Evaluasi kualitatif program penyakit tidak menular berbasis Posbindu di wilayah kerja Puskesmas Muara Bungo I. J Kebijak Kesehat Indones JKKI. 2018 Jun 1;7(2):88-92.

11. Kemenkes RI. Evaluasi Anggaran Kesehatan (Pelaksanaan Program Dekonsentrasi Dan Dak Bidang Kesehatan Tahun 2018). 2019.

12. Paramita S, Ismail S, Nuryanto MK, Putro TP. Optimalisasi Pos Pembinaan Terpadu Penyakit Tidak Menular Di Desa Loa Kumbar, Kecamatan Sungai Kunjang, Kota Samarinda, Kalimantan Timur. Jurnal Pengabdian Masyarakat Borneo. 2019 Jul 30;3(1):1.

13. Kemenkes RI. Petunjuk teknis pos pembinaan terpadu posbindu bagi kader [Internet]. 2019. 1-60 p. Available from:

http://p2ptm.kemkes.go.id/uploads/VHc rbkVobjRzUDN3UCs4eUJ0dVBndz09/ 2019/03/Petunjuk_Teknis_POSBINDU _B agi_Kader.pdf

14. Yanti NE, Lubis NL, Diana VE. Analisis Implementasi Kebijakan Puskesmas Dalam Program Pos Pembinaan Terpadu Penyakit Tidak Menular. MPPKI [Internet]. 2019 [cited 2020 Mar 11];2(3). Available from: https://doi.org/10.31934/mppki.v2i3 
